\title{
Sol-Gel Derived Nanoparticles as Inorganic Phases in Polymer- type Matrices
}

\author{
Helmut Schmidt \\ Institut für Neue Materialien, Im Stadtwald, Geb. 43, 66123 Saarbruecken, Germany
}

\section{SUMMARY}

The use of nanoparticles in hybrid and polymeric matrices has been investigated. Different types of nanocomposites have been prepared. The ormosil type based on organoalkoxy silanes shows surprising properties with respect to solid content and relaxation. Thick films for coatings, embossed films for diffractive purposes, high temperature stable binders for glass fiber insulation materials and printing pastes have been prepared. The nanomer type with nanoparticles homogeneously dispersed in polymer matrices led to optical adhesives with improved properties with respect to $\mathrm{T}_{\mathrm{g}}$ and thermal coefficient of expansion. The inverse nanomer type with the nanoparticles forming a percolating network was developed for photo curable optical interference layers on plastic, for example to AR coating by using simple wet chemical coating techniques.

\section{Introduction}

Hybrid materials have become a very interesting class between polymers and ceramics. Over a period of more than 20 years they have become a well established area in the field of sol-gel synthesis. This was mainly based on the properties of silicon to form stable bonds to oxygen and carbon at the same atom. Since silicon alkoxides have been used as model agents in many investigations ${ }^{1-14)}$. Meanwhile a variety of industrial applications has been reported for example as hard coatings ${ }^{15-18)}$, dental materials ${ }^{19)}$ or low-surface free energy coatings on sanitary ware ${ }^{20}$. Due to the manifold possibilities to combine inorganic with organic synthetical chemistry an almost endless variability of structures exists which opens up very attractive new synthesis routes for inorganic and organic chemists. From the industrial point of view that means market and commercialization, however, very often it is difficult to find out which route will lead to useful materials for application and very often cost versus performance problems prevent the realization of interesting potentials. Whereas inorganic-organic hybrid materials based on sol-gel synthesis have been considered as more or less molecular composites, more recently the hybrid materials in combination with particulate systems have become of interest ${ }^{21-33)}$. This systems may be called Nanomers ${ }^{34)}{ }^{35)}$ and one of the reasons for the development of this group of materials is based on the fact that inorganic nanoparticles in most cases show physical, chemical, optical or electronical properties which a single inorganic molecule 
does not show. Those properties may be semiconducting properties, non-linear optical properties or even catalytic properties. Another attractive property is the large interface of these particles which can become of importance because interfaces for example between the two phases always show properties different from the single phases. These interfacial phases may gain importance if their volume fractions become remarkable, for example as interfaces between nanoparticles and polymeric matrices. From the structural point of view, different classes of hybrid materials can be distinguished.

\section{Classes of materials}

\section{Types of hybrids}

Ormosils or organically modified silicates are describing a sol-gel derived material with a mainly inorganic backbone and modifying groups dispersed in this backbone. In figure 1a, a simplified structure of the type I (ormosil) is shown. In figure $1 \mathrm{~b}$, a more complex ormosil structure is shown, with organic chains as links between $\mathrm{Si}$-atoms. This type also

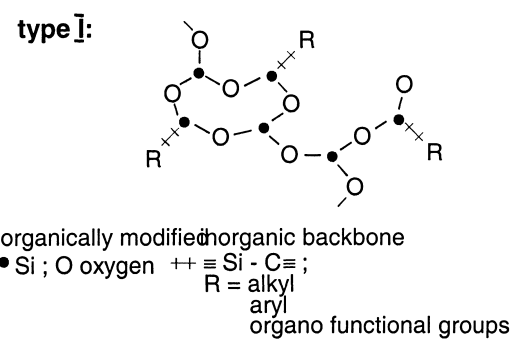

Fig. 1a: Type I hybrid material: ormosils Fig. 1b: Type II hybrid material ormosils with with out organic chains

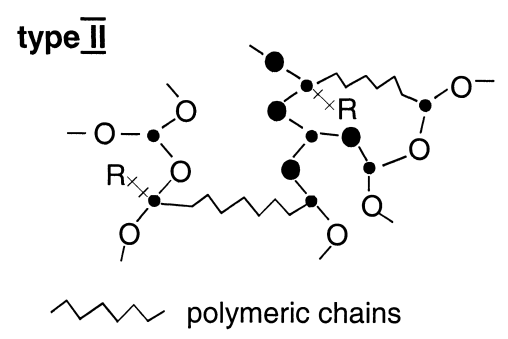

organic chains

may include interpenetrating organic chains or adsorbed organic molecules like dyes. As a type III structure, other elements as inorganic backbone former can be used, eg. $\equiv \mathrm{Zr}-\mathrm{O}-$, $\equiv$ Ti-O-, =Al-O- or others. To link organics to the inorganic ions, complex formation (eg. acetylacetonates), acid bases or chelating ligands can be used. These types also became known as ormocers, ceramers or polycerams. If the inorganic phase forms nanoparticles (oxides, metals or semiconductors), a type IV structure is formed with a type I-III as polymer matrix. This type is called nanomer (nano particle containing polymer type matrix), where the nanoparticle can be linked to the network or not. Figure 2 shows a structural model. For the fabrication of nanomers, different routes have been developed: 


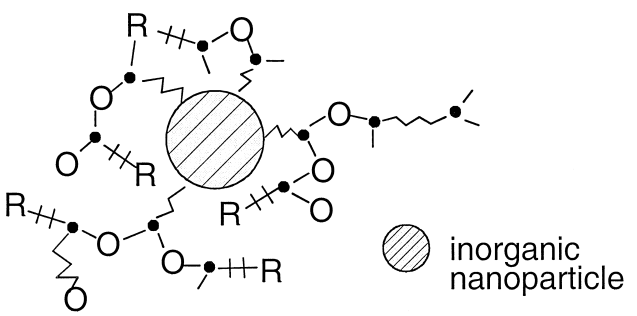

Fig. 2: Type IV hybrid material; nanomer type
The fabrication of nanoparticles in a seperate process ${ }^{36) 37)}$, based on a thermodynamical approach through a nucleation and growth process under the control of surface modifying agents. In figure 3 the nucleation frequency is shown as a function of various parameters (eq (1) and (2)), where $\sigma$ in eq (2) can be controlled by surface modifiers, (e.g. $\beta$ - diketones). As shown elsewhere in detail ${ }^{37)}$, the formation of

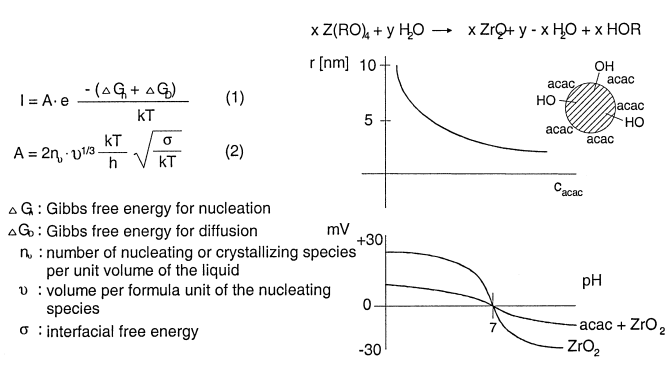

Fig. 3: Dependencies of the nucleation frequency $\mathrm{ZrO}_{2}$ nanoparticles can be controlled in size by the concentration of acac during hydrolysis and condensation. Due to the coverage of various amounts of acac, the $\zeta$ potential which depends on the concentration of acid or basic surface sites, shows lower values, but as expected, the point of zero charge (p.z.c) does not change. In addition to the $\zeta$-potential effect, the surface modification also can reduce the particle to particle interaction to the Van der Waals or weak dipole interaction and thus prevents the formation of hard agglomerates. Weakly agglomerated surface modified powders have been obtained from many systems (figure 4), fully redispersible due to the appropriate surface modification ${ }^{36) 38-40)}$. 
$\mathrm{Y}-\mathrm{ZrO}_{2}$

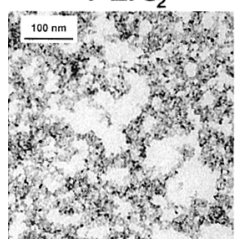

PZT

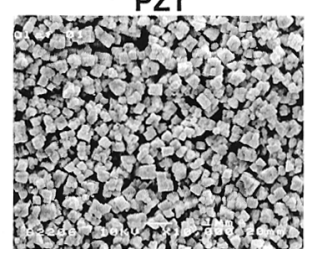

ITO

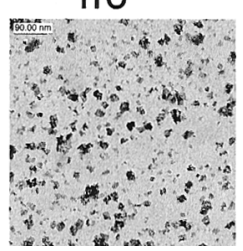

$\mathrm{SnO}_{2}$

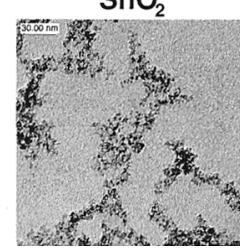

Fig. 4: Examples of agglomerate-free nanoparticles (after ${ }^{36)}$ )

\section{Ormosils}

One of the simplest examples for ormosils are hybrids fabricated from tetraethylorthosilicate and alkylalkoxysilanes. This type of ormosils have been used as so called spin-on glasses in microelectronics ${ }^{40)}$ or as mild abrasives for skin treatment ${ }^{41}$. Since the alkylsilanes are reducing the network-connectivity and as a consequence the brittleness of the spin-on glasses also will be reduced, liquids are obtained which can be used in coating processes like spin- and dip coating. However, the film thickness which can be obtained by this method is rather limited. In a spin or dip coating process one or two $\mu \mathrm{m}$ can not be exceeded. This phenomenon has been investigated from Fred Lange and co-workers which found out that in given sol-gel systems, the strength of the material, the shrinkage during drying and firing, the solid content and the relaxation behavior are the most important parameters for the obtainable film thickness. They concluded that in sol-gel materials thickness above $1 \mu \mathrm{m}$ are difficult to obtain. Since the extend of shrinkage is directly connected with solid content of a dried film, the solid content in gels in general is far away from the theoretical package density due to the increasing brittleness of the inorganic network during condensation which leaves pores and voids in the structure. It seemed to be of interest how far this draw back could be overcome by substituting a part of a sol-gel-derived $\mathrm{SiO}_{2}$ from hydrolysis and condensation of TEOS (tetraethylorthosilicate) and MTEOS (methyltrietoxysilane) by already condensed $\mathrm{SiO}_{2}$ in form of nanoparticles. For this reason, colloidal silica has been used in form of aqueous suspension (Bayer chemical company) and reacted with TEOS and MTOS or methyltrimethoxysilane (MTMEOS) respectively. The experimental process is described in detail elsewhere ${ }^{42,43)}$. As a measure for the influence of $\mathrm{SiO}_{2}$ nanoparticles, the critical thickness was measured and defined as a thickness of a film obtained by a one step dip-coating process after firing at $500{ }^{\circ} \mathrm{C}$ on silica substrates without showing a single crack. In the dependence of the critical thickness as a function of the $\mathrm{SiO}_{2}$-content is shown. As one clearly can see, the critical thickness increases strongly with the increasing $\mathrm{SiO}_{2}$-content and reaches a 
maximum at about $40 \%$ with values around $14 \mu \mathrm{m}$ (figure 5). The MTMEOS system

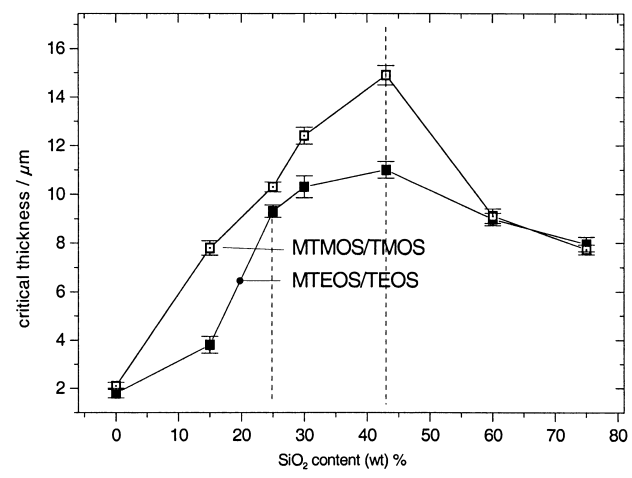

Fig. 5: Critical thickness as a function of the $\mathrm{SiO}_{2-}$ content in different ormosils shows a little bit higher values than MTEOS. If the solid content exceeds 40 wt.- $\%$, the critical thickness decreases which can be interpreted with the fact that the relative concentration of methyl groups in the system is reduced more and more leading to an increased particle interaction approaching typical inorganic solgel coating thicknesses. It was of interest to investigate whether there are other effects of the $\mathrm{SiO}_{2}$ nanoparticles on the condensation kinetics of the system. For this reason, a $\mathrm{T}$ - andQ-Ana lysis were carried out in the $\mathrm{SiO}_{2}$-containing and in the $\mathrm{SiO}_{2}$-free system. In figure $6 \mathrm{a}$ and $\mathrm{b}$ the $\mathrm{T}$ analysis is given. ( $\mathrm{T}$ and $\mathrm{Q}$ analysis show the connectivity of condensed silans: $\mathrm{T}^{1}$ means a Si-R connected by one oxygen bridge to another $\mathrm{Si}: \mathrm{R}-\mathrm{Si}-\mathrm{O}-\mathrm{Si} \equiv, \mathrm{T}^{2}$ means two bridges an so on. $\mathrm{Q}^{1}$

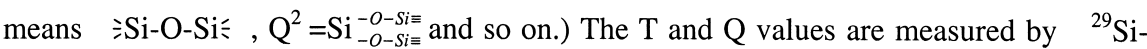
NMR spectroscopy. Figure 6 clearly shows that the $\mathrm{SiO}_{2}$-nanoparticle containing systems lead to lower $\mathrm{T}^{2}$ and higher $\mathrm{T}^{3}$ values after the same reaction times. For $\mathrm{Q}^{3}$ and $\mathrm{Q}^{4}$ a similar
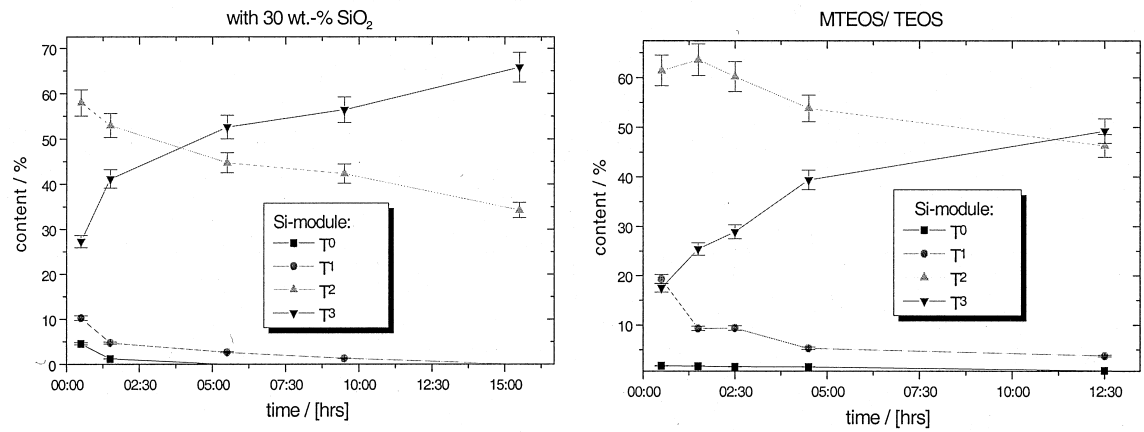

Fig. 6a: $\mathrm{T}^{0}-\mathrm{T}^{3}$ measurements for Fig. 6b: MTEOS/TEOS without $\mathrm{SiO}_{2}$ MTEOS/TEOS with $\mathrm{SiO}_{2}$

behavior is observed. However, the increased condensation kinetics does not explain the higher critical thickness. The particle size analysis as a function of time (agening) shows that in the $\mathrm{SiO}_{2}$-sol containing systems the particle size increase is much faster than in the 
$\mathrm{SiO}_{2}$-sol free systems (3-400 $\mathrm{nm}$ versus 6-800 nm). As photon correlation spectroscopy measurements as a function of the aging time show, this can be interpreted by a type of "nucleation effect", with the hybrid sol forming a gel-like structure around the $\mathrm{SiO}_{2}$ nanoparticles. It is anticipated that a core-shell structure is formed as schematically shown in figure 7. As shown in ${ }^{44)}$, during drying of hybrid gels the formation of hydrophobic

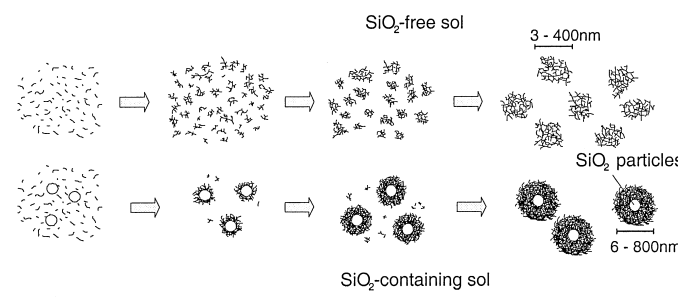

Fig. 7: Structure formation in the silica particle containing MTEOS/TEOS systems; particle sizes measured by PCS. pores takes place, measured by absorption isotherms with water vapor. This leads to the conclusion that methyl-groups are preferringly present in interfaces thus reducing the particle to particle interaction, which otherwise would be very strong by the formation of $\mathrm{Si}-\mathrm{O}-\mathrm{Si}$ or hydrogen bonds. This structure should lead to an enhanced relaxation. Following the hypothesis of an enhanced flexibility as an important reason for the increased critical thickness, the burn out temperatures of $\mathrm{CH}_{3}$ was investigated by TGA and DTA measurements. The oxidation peaks maximum of methyl groups and ethoxy groups have been evaluated and the maximum temperatures are shown in figure 8 . As one clearly can see, as a function of the $\mathrm{SiO}_{2}$-content, the oxidation peak of the methyl-group is shifted

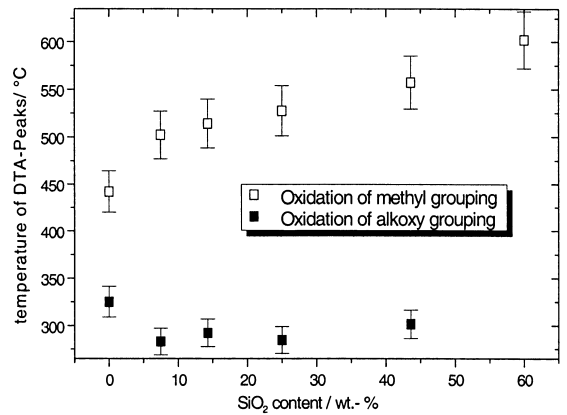

Fig. 8: Oxidation peaks maximum of methyl groups and ethoxy groups from $440{ }^{\circ} \mathrm{C}$ to $600{ }^{\circ} \mathrm{C}$. This means that by establishing the appropriate $\mathrm{SiO}_{2}$-content a temperature can be chosen where the methylgroups disappear. In figure 9 a-b the corresponding IR-spectra are shown, also clearly depicting the higher temperature stability of $\mathrm{SiO}_{2}$-sol containing systems (peaks at the 2900 and $1250 \mathrm{~cm}^{-1}$ regium). These results support the hypothesis of an increased relaxation at higher temperatures as an important factor for an increased critical thickness. To investigate the effect of these coatings on glass fibers, a fiber sample coated with the $\mathrm{SiO}_{2}$ - containing sol was investigated in a fiber elongation viscosimeter (figure 10). The results show that up to $1000^{\circ} \mathrm{C}$ no viscous flow is detectable. Moreover, above $T_{g}$ 


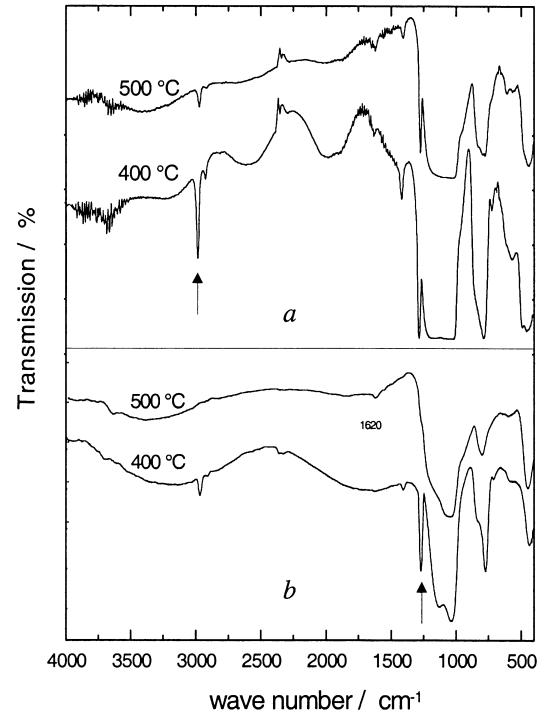

Fig. 9a: MTEOS/TEOS / 25\% $\mathrm{SiO}_{2}$, Fig. 9b: MTEOS/TEOS without $\mathrm{SiO}_{2}$

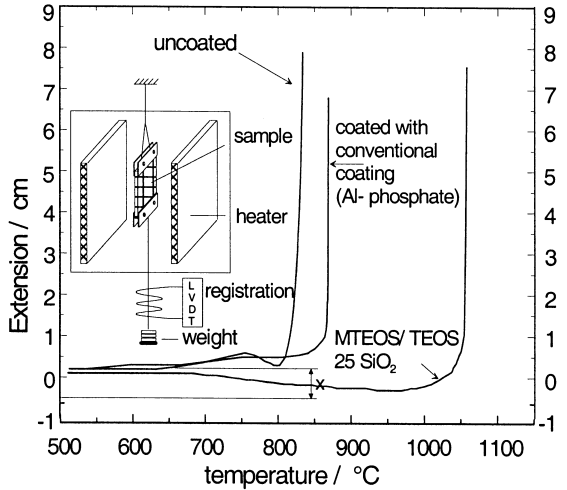

Fig. 10: Fiber elongation viscosimetry of uncoated Al-phosphate and $\mathrm{SiO}_{2}$ sol coated fibres

of the basic glass a contraction ( $\mathrm{x}$ in figure 10) is observed, which is attributed to the sintering process of the coating. This means, that a densification takes place without a viscous flow mechanism. Otherwise a contraction against the elongation force of the viscosimeter should not be possible. Summarizing one can say that based on a structure model, a highly relaxable sol-gel coating system could be developed which leads to a substantial increase of the critical thickness compared to conventional sol-gel systems. This type of ormosils can be considered as ormosil nanocomposites. The sintering and densification of a gel with a composition of $\mathrm{SiO}_{2}$ glass without viscous flow opens up the possibility to use these materials as inorganic high temperature resistant binders with the advantage not to change the shape pf the part by viscous flow. As shown by Mennig et. al, gel layers can be embossed at room temperature and then transferred into $\mathrm{SiO}_{2}$ glass without changing the shape of the patterns ${ }^{45)}$. As recently shown by Kalleder et al. ${ }^{46)}$, the system has been used as binder for fine-line printing processes with $\mathrm{Ag}$ as conductive agent. By mixing silver powder with only about $2 \%$ of the described $\mathrm{SiO}_{2}$-containing binder and screen printing additives, a printing paste could be synthesized having an viscosity appropriate for fine-line printing. Conventional conductive printing pastes are based on glass frits as a viscous flow binder which only can be densified above the $T_{g}$ of the glass. This leads to a viscous flow and as a consequence in restrictions in the line shape (roundening) and in the line distances (broadening). This does not take place with the new nano-based binder ormosil, since viscous flow sintering is avoided. The paste was prepared by using the $\mathrm{SiO}_{2}$ containing sol and by mixing it with $\mathrm{Ag}$ 
$(30 \mu \mathrm{m})$, tetraethylene glycol and hydroxypropylcellulose ${ }^{47)}$ to obtain the required rheology. After printing the lines were heated to $570{ }^{\circ} \mathrm{C}$ for $20 \mathrm{~min}$ without a broadening to be observed. In figure 11, a printed pattern is shown. No uncontrolled line broadening takes place. Other interesting applications are embossing techniques. The ormosil nanocomposite

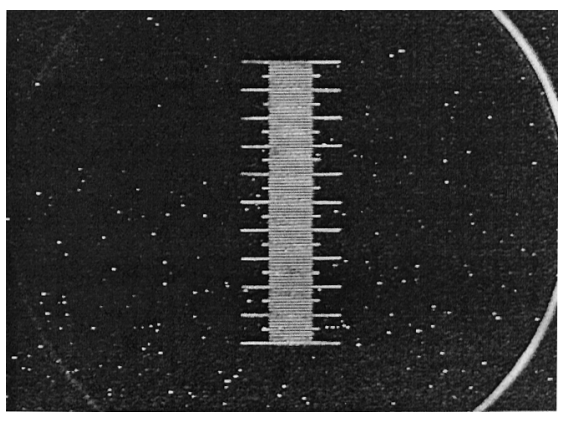

film can be easily embossed after coating since due to the reduced particle-to-particle interaction the film is very soft (soft gel film, SGF) (figure 12). Silicone rubber stampers can be used to emboss these systems. Due to the very soft gels, silicone rubber stampers or rolls can be used, making this process cheap. In figure 13, embossed light traps on Fig. 11: a $1 \mathrm{~mm}$ in length grid line a glass

substrate for the efficiency increase of solar collectors and a hologram embossed on a metal substrate are shown. The films not only can be prepared from $\mathrm{SiO}_{2}$, but also from $\mathrm{TiO}_{2}$ nanoparticles to produce high refractive index patterns. The $120^{\circ} \mathrm{C}$ cured coating

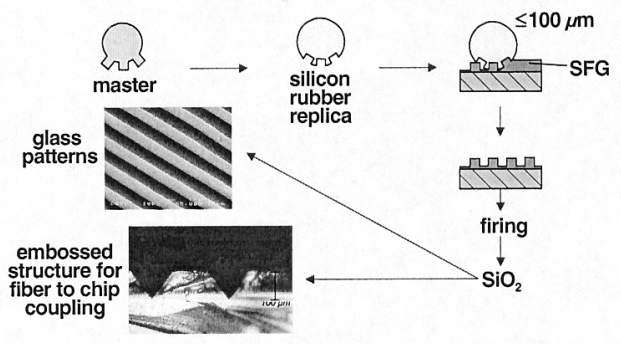

Fig. 12: Principles of the process for making micropatterns using ormosil nanocomposites (SGF-process)

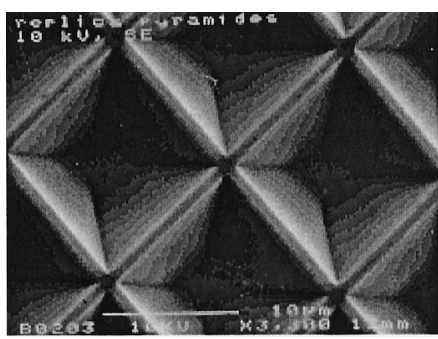

Fig. 13: Glass light traps on solar collectors

systems show high flexibility compared to inorganic sol-gel coatings and, due to the reduced burn out kinetics of the methyls, this elasticity is maintained up to higher temperatures. This led to the idea to investigate how far this system can be used as a new binder for glass fiber mats. For this reason, the binder was sprayed on an uncoated glass fiber and the elasticity was measured. In figure 14 the result is shown. The glass fiber mat behaves the same way as conventional phenolic resin bonded glass fibers (figure 14). This results have been used to build up an industrial process for the fabrication of ormosil bonded glass fibers. The organic content of these glass fibers is only in the range of $2 \%$ 


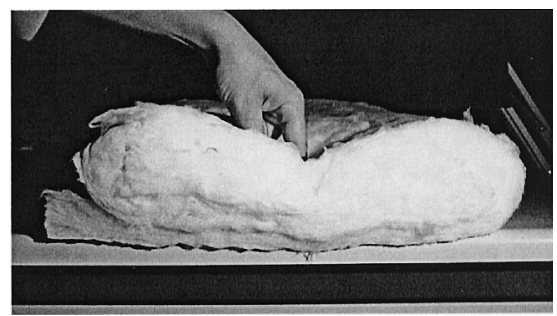

Fig. 14: "White" glass fiber mats showing very elastic behavior

Dämmstoffe Company, Germany. which means that in the case of fire no poisonous crack products are produced. The glass fiber mat withstands temperatures up to $600{ }^{\circ} \mathrm{C}$ without losing their insulating properties. It can be easily recycled and used as fire insulation materials. The process was commercialized with Pfleiderer

\section{Nanomers}

The dispersion of nanoparticles in more polymer-like matrices leads to the concept of

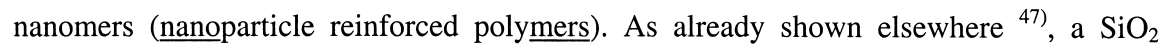
particle reinforced adhesive for fiber to chip coupling has been developed by use of a high degree of filling of epoxides. Detailed investigations about the incorporation of the $\mathrm{SiO}_{2}$ nanoparticles have shown that it is of great importance for obtaining a homogenous dispersion to control the surface free energy of these particles in order to adapt them to the polymeric matrix system. As polymeric matrix system an uncured epoxy-system and as fillers $6 \mathrm{~nm} \mathrm{SiO}$ from commercially available sols have been used. The idea was to investigate how far the polymer properties with respect to the cte (coefficient of thermal expansion), modulus and $\mathrm{T}_{\mathrm{g}}$ may be affected advantageously without disturbing application properties like viscosity. It has to be kept below $15 \mathrm{mPas} \cdot \mathrm{s}$, since the adhesive has to be filled into a narrow slit of $3 \mu \mathrm{m}$ (figure 15). For this reason the viscosity has been

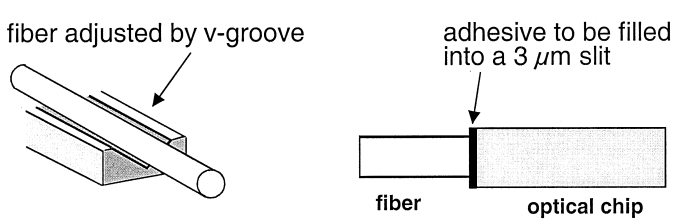

Fig. 15: Principle of fiber to chip coupling by hydrophilic OH-group containing adhesive bounding investigated as a function of the silica content. From interfacial thermodynamical considerations it was clear that the silica surface has to be modified in order to reduce the interfacial free energy because the epoxy monomer. On the other hand the surface modification should not contribute substantially to the volume in order not to change the properties of the polymerized system. For this reason tetramethylammoniumhydroxid (TMAH) has been chosen, since, 
due to the polarity of the surface of the $\mathrm{SiO}_{2}$ and the molecule a reasonable interaction between the two components was anticipated. The TMAH would not be a perfect surface modifier in aqueous systems but it was expected to be so in non-aqueous systems. In figure 16 the influence of surface modification and $\mathrm{SiO}_{2}$-content on the viscosity is shown. As one

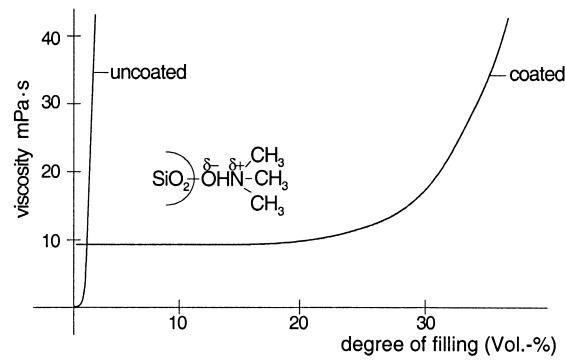

Fig. 16: Viscosity of the uncured epoxy as a function of the $\mathrm{SiO}_{2}$ (uncoated and coated with TMAH) clearly can see, in the unmodified case the viscosity increases drastically with very low $\mathrm{SiO}_{2}$-content leading to not usable systems. After the surface modification with TMAH the viscosity remains stable up to 20 or 25 vol.-\% (representing about 40 weight-\%) of $6 \mathrm{~nm} \mathrm{SiO}_{2}$. The properties of the polymers change remarkable. In figure 17 , the TEM micrograph of a sytem filled with about 25 vol- $\%$ of $\mathrm{SiO}_{2}$ is shown. It clearly depicts the homogeneous densification of $\mathrm{SiO}_{2}$. In figure 18 the modulus as a function temperature and $\mathrm{SiO}_{2}$-content is shown. With increasing

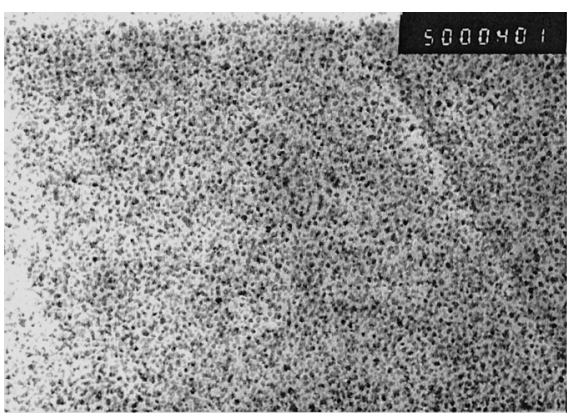

Fig. 17: TEM micrograph
$\mathrm{SiO}_{2}$-content a rubbery plateau is formed above $\mathrm{T}_{\mathrm{g}}$. The cte also is changing remarkably. (From 200 to $150 \cdot 10^{-6} / \mathrm{K}$ in the $120^{\circ} \mathrm{C}$ regime and from 110 to $80 \cdot 10^{-6} / \mathrm{K}$ in the $50{ }^{\circ} \mathrm{C}$ regime). The new nanocomposite adhesive shows several advantages: lower shrinkage, no part curing, faster curing and is commercialized already ${ }^{48)}$. A completely different type of nanomers is accessible by "inversal structure", meaning that not the polymer forms the percolating phase but the nanoparticles. The details are described elsewhere ${ }^{48)}$. In this case $\mathrm{TiO}_{2}$ and $\mathrm{SiO}_{2}$ nanoparticles prepared by a sol-gel route have been modified with glyceroloxypropyl triethoxysilane $\left(\mathrm{TiO}_{2}\right)$ and methacryloxypropyl 


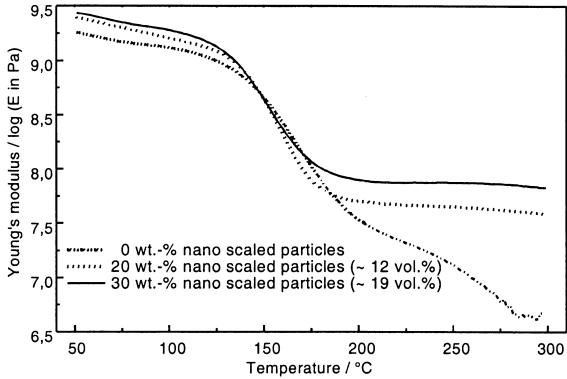

Fig. 18: Young modulus vs. temperature for $\mathrm{SiO}_{2}$ containing nanocomposites triethoxysilane $\left(\mathrm{SiO}_{2}\right)$, respectively. If these nanoparticle sols are used for coatings on polymers, for example by a dip coating process, they can be photo-polymerized if the appropriate photo-catalysts are added (radical photo-initiators for the methacrylates and ionic photo-initiators for epoxides) ${ }^{49)}$. Measuring the density of these materials by various methods leads to the surprising effect that the package density is much higher as expected, for example in the case of $\mathrm{SiO}_{2}$ refractive indices above 1.9 have been obtained suggesting a package density in the range of $90 \%$ of the theoretical density. In the schematic process of the layer formation is given (figure 19). Using this technique, interference layers (from $\mathrm{SiO}_{2}$ and $\mathrm{TiO}_{2}$ ) have been fabricated on plastics, only using a wet coating process in combination with photocuring. In figure 20 an interference filter is shown, produced by dip coating and angle dependant dip coating. Summarizing it is to say that this technique leads to a completely new class of nanomers that means polymers which do not have a polymeric chain but nanoparticles which are connected by short organic links which makes them flexible enough to be used on polymers which show an extremely high package density. More investigations of this type of materials is necessary in order to learn more about structure and properties ${ }^{49}$.

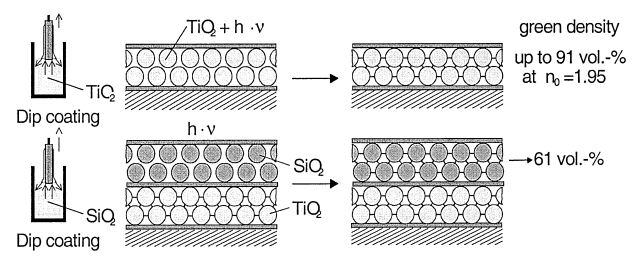

Fig. 19: Interference filters produced by the universal nanomer process on polycarbonate 


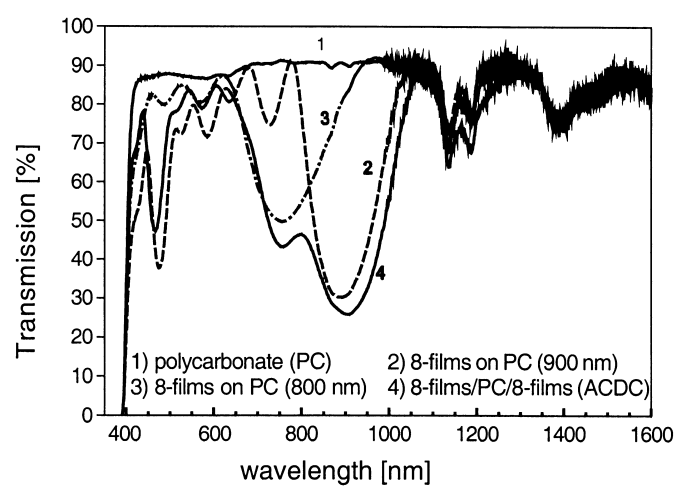

Fig. 20: Scheme of the process of the formation of synthesized by using various microsol nanomer layers

\section{Conclusions}

The combination of polymer type of materials with inorganic components can lead to interesting materials with a high potential for industrial applications. A different type of structures can be inorganic or organic precursors and properties depend strongly on these structures. And moreover the introduction of nanoparticles leads to additional tools for material tailors. First by the functional properties of the nanoparticles for example by effecting the reaction kinetics and second by the generation of an interfacial face to the polymer which is different in structure from the environment and which leads to a change of the polymer properties. In addition to this the nanoparticles may lead to so called inversed structures, a class of materials which has not been investigated in detail so far.

\section{Acknowledgment}

The authors greatly acknowledge the financial support of the industry, the State of the Saarland for the work.

\section{References:}

1. H. Krug, H. Schmidt, Proc. of Eur. Wsh. Hyb. Org.-Inorg. Mat. Syn., Prop., Appl. 1, 127-141, (1993)

2. R. Kasemann, H. Schmidt, Proc. of Eur. Wsh. Hyb. Org.-Inorg. Mat. Syn., Prop., Appl. 1, 171-180, (1993)

3. D. Hoebbel, T. Reinert, K. Endres, H. Schmidt, A. Kayan, E. Arpac, Proc. of Eur. Wsh. Hyb. Org.-Inorg. Mat. Syn., Prop., Appl. 1, 319-323, (1993)

4. H. Schmidt, P. W. Oliveira, H. Krug, MRS Symposia Proceedings, 435, 13-14, (1996)

5. V. Gerhard, H. Schmidt; U. Dreier, MRS Symposia Proceedings, 435, 455-460, (1996)

6. P. Müller, C. Becker, H. Schmidt, MRS Symposia Proceedings, 519, 387-393, (1996)

7. H. Schmidt, E. Arpac, H. Schirra, S. Sepeur, G. Jonschker, MRS Symposia Proceedings, 519, 297-308, (1998)

8. H. Schmidt, E. Geiter, M. Mennig, H. Krug, C. Becker, R.-P. Winkler, J. Sol-Gel Sci. Tech. 13, 397-404, (1998)

9. M. Mennig, M. Zahnhausen, H. Schmidt, Proc. of SPIE, 3469, 68-78, (1998)

10. C. Becker, P. Müller, H. Schmidt, Proc. of SPIE 3469, 88-98, (1998)

11. H.K. Schmid, M. Aslan, S. Assmann, R. Nass, H. Schmidt, J. Eur. Cer. Soc. 18, 1, 39 49, (1998)

12. H.K. Schmid, Proc. of EUROMAT 5, 5-10, (1997) 
13. H. Schmidt, H. Krug, B. Zeitz, E. Geiter, Proc. of SPIE 3136, 220-228, (1997)

14. P. Judeinstein, P.W. Oliveira, H. Krug, H. Schmidt, Adv. Mat. Op. Elec. 7, 123-133, (1997)

15. G.W. Wagner, S. Sepeur, R. Kasemann, H. Schmidt, Proc. of Sol-Gel Production, $193-$ 198, (1998)

16. H. Schmidt, B. Seiferling, G. Philipp, K. Deichmann, Proc of Ultrastr. Proces. Cer., Glas. Comp., Wiley, 651-660, (1988)

17. R. Kasemann, H. Schmidt, N. J. Chem. 18, 10, 1117-1123, (1994)

18. S. Langenfeld, G. Jonschker, H. Schmidt, Mat. Wiss. Werkst. 28, 1-15, (1997)

19. H. Wolter et al. DE-PS 4133494 C2 (28.3.1996)

20. Technical information about "Wondergliss", Duravit, (1999)

21. J. E. Mark, Proc. of Int. SAMPE Tech. Conf., 27, 539-548, (1995)

22. T. Saegusa, Proc. of Macromol. Symp., 719-29, (1995)

23. B. M. Novak, M. W. Ellsworth, C. Verrier, Polym. Mater. Sci. Eng., 70, 266-7, (1993)

24. C. L. Beaudry, L. C. Klein, Polym. Mater. Sci. Eng., 73, 431-2, (1995)

25. C. L. Beaudry, L. C., Klein, Proc. of ACS Symp. Ser., 622, 382-94, (1996)

26. J. Wen, G. L. Wilkes, Chem. Mater., 8(8), 1667-1681, (1996)

27. P. B. Leezenberg, M. D. Fayer, C. W. Frank, Pure Appl. Chem., 68(7), 1381-1388, (1996)

28. Z. Gao, Z. Zhao, Y. Ou, Z. Qi, F. Wang, Polym. Int., 40(3), 187-192, (1996)

29. M. I. Sarwar, Z. Ahmad, Adv. Mater., 73-77, (1997)

30. M. Motomatsu, T. Takahashi, H.-Y. Nie, W. Mizutani, H. Tokumoto, Polymer, 38(1), $177-182,(1997)$

31. J. F. Gerard, H. Kaddami, J. P. Pascault, Proc. of Eurofillers 97, 407-410, (1997)

32. A. B. Wojcik, A. Ting, L. C. Klein, Mater. Sci. Eng., C, C6(2,3), 115-120, (1998)

33. E. Reynaud, C. Gauthier, J. Perez, Rev. Metall./Cah. Inf. Tech., 96(2), 169-176, (1999)

34. B. Braune, P. Müller, H. Schmidt, Proc. of SPIE, 3469, 124-132, (1998)

35. Chemistry and technology of nanoparticles: preparation, processing and application. Proc. of EUROMAT, 5-10, (1997)

36. H. Schmidt, R. Nonninger, Proc. of Fine, Ultrafine and Nano Powders '98, (1998)

37. H. Schmidt, Kona powder and particle (14), 92-103, (1996)

38. R. Nass, S. Albayrak, M. Aslan, H. Schmidt, Proc. of CIMTEC, 11, 47-54, (1995)

39. R. Nass, S. Albayrak, M. Aslan, H. Schmidt, ACerS, 51, 591-595, (1995)

40. A. M. Ron, M. Fibich, Sol. St. Commun., 58(12), 869-72, (1986)

41. H. Schmidt et al. Abrasiv wirkende Mittel und deren Verwendung DE-PS 3048369 C2 (5.1.1983)

42. G. Jonschker, Ph. D. Thesis, University of Saarland, Saarbrucken, Germany (1998)

43. H. Schmidt, G. Jonschker, S. Goedicke, M. Mennig, Proc. of $10^{\text {th }}$ Int. Ws. on Glas., Cer., Hyb. Nanocomp., in print (1999)

44. H. Schmidt, H. Böttner, Iler 91-Symposia, Advances in Chem. Ser. 234 ACS, 419-432, (1994)

45 M. Mennig, G. Jonschker, H. Schmidt, Proc. of SPIE, 1758, 125-134, (1992)

46. A. Kalleder, R. Kreutzer, M. Mennig, H. Schmidt: Proc. of Euromat 99, in print

47. Th. Koch, M. Mennig, H. Schmidt, Proc. of CIMTEC, 17, 681-688, (1999)

48. H. Krug et al, Nanostrukturierte Formkörper und Schichten sowie Verfahren zu deren Herstellung. DE-OS, 19719948 A1 (19.11.1998)

49. M. Mennig, P.W. Oliveira, A. Frantzen, H. Schmidt, Proc of 2nd ICCG, 351, 225-229, (1998) 
